\section{Israel must release Palestinian physicist}

On 24 April, the distinguished Palestinian astrophysicist Imad Ahmad Barghouthi was arrested and detained without charge by the Israeli military - for the second time in less than 18 months (see Nature http:// doi.org/bk44; 2016). We protest against his imprisonment and renew the call for his release.

Once again, it was alleged that Barghouthi made statements on Facebook and on television in opposition to Israeli military attacks and occupation.

Subsequent international pressure again contributed to a ruling by the military court of appeals a month later for his release (see go.nature.com/299v9nd). This has not happened. Barghouthi has instead been transferred to a facility run by Israel's internal security service, Shin Bet, for further interrogation.

Ahmed Abbes* IHES, CNRS, Paris, France.

abbes@ihes.fr

*Supported by 13 signatories

(see go.nature.com/29btttb).

\section{Build social costs into wildfire risk}

Marc-André Parisien calls for the fire-science community to draw up maps of wildfire risk based on contributory factors such as local topography, vegetation and weather (Nature 534, 297; 2016). I suggest that incorporating social and economic risks into such maps would increase the effectiveness of fire-management policies.

The insurance and housing industries are likely to discourage construction of fire-sensitive structures in zones designated as high risk in wildfire maps. We therefore need proper accounting of the implications of fire-risk mapping for zoning, taxation and insurance fees. For example, introducing these maps could affect rural communities, which may have to pay higher premiums or be denied fire insurance.
We do not yet fully understand how to project human-caused fire risk. Demographics may explain global shifts in pyrogeography (W. Knorr et al. Nature Clim. Change http://doi.org/bkqn; 2016); changing land use and agricultural practices also contribute.

National fire-risk mapping systems will need to take into account local differences in governance and attitudes if they are to be effective at regional or community levels. There may be mismatches in ecosystem vulnerability, fire policies and acceptable degrees of fire risk. In the United States, for example, prescribed burning for habitat restoration is relatively new in Pennsylvania, but long established in neighbouring New Jersey.

Erica A. H. Smithwick Pennsylvania State University, University Park, USA. smithwick@psu.edu

\section{Entice Africa's scientists to stay}

The Dakar Declaration was put forward at the 2016 global meeting of the Next Einstein Forum held in Dakar, Senegal. It focuses on advancing African science, technology, engineering and mathematics (STEM), with particular encouragement for women and young scientists (go. nature.com/29ra0k6; see also Nature 531, 275; 2016). Previous attempts to create a scientific identity for Africa have met with limited success, so it is crucial to improve the continent's research environment if we are to realize and maintain its potential.

In many African countries, this research environment is characterized by sparse financial, human and capital resources, lack of opportunities and inadequate infrastructure. Such conditions drive many young and talented scientists to leave for other parts of the world.

In our view, plans to move STEM forward in African countries should focus on strategic utilization of scientific research for economic and societal development. Restructuring of the governance of science and technology is essential for a knowledge-based economy. The call to invest more in promising young African scientists should encourage their reintegration into their home countries after working and studying abroad — and prevent a brain drain in the long term. Ghada Bassioni Ain Shams University, Cairo, Egypt. Gameli Adzaho Weija, Ghana. David Niyukuri University of Burundi, Bujumbura, Burundi. ghada_bassioni@eng.asu.edu.eg

\section{Speed restoration of EU ecosystems}

The European Union's

Biodiversity Strategy 2020 aims to restore at least $15 \%$ of degraded ecosystems by 2020 , in accordance with the 2010 Aichi targets. With these due for review later this year, we are deeply concerned about Europe's lack of progress towards meeting its own target. In our view, EU member states need to engage properly in the repair of their damaged ecosystems.

All member states failed to honour their commitment to deliver a sound national restoration prioritization framework by the end of 2014, an initiative intended to improve the quality, scale and consistency of ecosystem restoration. This was profoundly disappointing, given the poor state of the environment in large parts of Europe and the need to develop resilience against climate change.

We urge the European Commission and member states to rectify this potentially costly inaction. Ecosystem restoration must be fully integrated into EU and national policies and land-use planning. Fact-based guidelines and regulations should be issued and standards set up for evaluation and progress. Provision of additional earmarked funds is essential to boost cost-effective restoration.

Countries with a robust restoration plan and confirmed restoration efforts could be rewarded with access to further EU funding. It is also important to publicize the benefits of restoration for social well-being. Jordi Cortina-Segarra University of Alicante, Spain. Kris Decleer Research Institute for Nature and Forest, Belgium. Johannes Kollmann Technical University of Munich, Germany. jordi@ua.es

\section{Citizens arrest river pollution in China}

We would like to share the story of how local citizens have helped to clean up polluted rivers in Zhejiang province in China.

Three years ago, the regional government allocated 140 billion yuan (US $\$ 21.5$ billion) to the clean-up operation. It launched a campaign to alert the local population of 55 million to the severity of the pollution and the risk to public health, and to publicize its plans and the benefits in the long term. As a result, Zhejiang citizens support the project and voluntarily cooperate to implement it.

Individual rivers are overseen by a government official and a technology expert, whose contact details are posted at the riverside so that the public can promptly report illegal polluted discharges from factories and other sources. The officers then order these discharges to be cut off, knowing that their own promotion depends on swift action and improvements in water quality.

This overall strategy has markedly increased urban water quality (go.nature.com/292hwbi; in Chinese). It has also enabled the government to economize on monitoring equipment.

Tuqiao Zhang, Feifei Zheng, Tingchao Yu Zhejiang University, Hangzhou, China. feifeizheng@zju.edu.cn 